\title{
SWINBURNE ON SUBSTANCES, PROPERTIES, AND STRUCTURES
}

\author{
WILLIAM JAWORSKI
}

Fordham University

Mind, Brain, and Free Will, Richard Swinburne's stimulating new book, covers a great deal of territory. I'll focus on some of the positions Swinburne defends in the philosophy of mind. Many philosophers are likely to have reservations about the arguments he uses to defend them, and others will think his basic position is unmotivated. My goal in this brief discussion is to articulate some of the reasons why.

\section{SWINBURNE'S ARGUMENT FOR PROPERTY DUALISM}

Swinburne defends substance dualism, the claim that we are pure mental substances, ones that have only pure mental properties essentially. Pure mental properties are properties whose instantiation does not entail the instantiation of any physical properties. The property of seeing a desk is an impure mental property on Swinburne's view since necessarily someone can see a desk only if he or she is causally affected by one, and being causally affected by a desk is a physical property. Seeming to see a desk, however, entails no such condition; I can seem to see a desk even if there is no desk causally affecting me. A property $P$ is mental, according to Swinburne, exactly if a substance $S$ which instantiates $P$ necessarily has privileged access to $P$ 's instantiation. If $P$ is mental, then $S$ can in principle know that he or she instantiates $P$ in the same ways other substances know it, but there will be an additional way that $S$ knows that $P$ is instantiated, namely by experiencing it. Properties that are not mental are either physical or neutral. Physical properties are ones to which necessarily a substance does not have privileged access, and neutral properties are ones to which some substances have privileged 
access but others don't (disjunctive properties such as the property of being in pain or weighing $50 \mathrm{~kg}$ are examples; both I and the desk instantiate this property, but I have privileged access to its instantiation and the desk does not).

Swinburne argues that mental and physical properties are distinct. This follows a priori, he says, from his definitions of 'mental' and 'physical' in conjunction with his account of properties. Properties, according to Swinburne, are universals, and they are abundant: any predicate whatsoever, it seems, picks out a property, and two properties are identical exactly if their informative designators are logically equivalent (this is no slip of the tongue: Swinburne is quite serious about stating conditions under which two substances, or two properties, or two events are the same, and by this he appears to mean numerically the same; although he does not endeavour to explain how two things can be one). An informative designator of some substance, property, or event, $X$, is a rigid designator of $X$ that expresses $X$ 's nature or essence, the conditions metaphysically necessary and sufficient for $X$ being what it is. If 'red' is an informative designator, then the criteria for correctly applying it include the conditions that are metaphysically necessary and sufficient for being red. If those criteria are not logically equivalent to the criteria for correctly applying, say, 'reflects such-and-such wavelengths of light', then being red and reflecting such-and-such wavelengths of light must be different properties. This is in fact the case, says Swinburne, for knowing that something reflects such-and-such wavelengths of light does not entail that it looks a certain way to most people. The latter is an additional fact about an object that goes beyond its reflecting suchand-such wavelengths of light. It is thus true a priori that red is not identical to reflecting such-and-such wavelengths of light. It is also true a priori that redness does not supervene on reflecting such-and-such wavelengths of light, for it is logically possible that objects which reflect such-and-such wavelengths of light might look differently to us. What is true of red, according to Swinburne, is also true of mental properties; they are neither identical to nor supervenient upon physical properties. The criteria for correctly applying mental predicates and terms are not logically equivalent to the criteria for correctly applying physical ones; knowing that the former apply does not entail knowing that the latter apply and vice versa. Consequently, mental predicates and terms must designate properties distinct from those designated by physical predicates and terms. 
The crucial premise in Swinburne's argument is that terms like 'red' and 'pain' are informative designators, that in applying them we grasp the conditions that make redness and pain what they essentially are. The obvious challenge to this premise comes from people like Kripke and Putnam who have built philosophies of language around examples in which competent speakers apply terms correctly while failing to grasp the essence of what the terms apply to. The term 'water' is an example: many people use it correctly to refer to water without knowing that water consists of hydrogen and oxygen atoms. Many philosophers are inclined to view terms like 'red' and 'pain' by analogy with 'water'. We can be competent in applying them and making simple inferences to and from their application (if something is bright red, then it is red; if something is red, then it is coloured, and so on) while yet remaining ignorant of what makes them what they are. If that is the case, then Swinburne's property dualism cannot be established a priori, as he claims.

Swinburne acknowledges that 'water' is not an informative designator in his sense. Prior to discovering that water was $\mathrm{H}_{2} \mathrm{O}$, he says, people did not fully know what they meant by 'water'. But, he insists, terms like 'red' and 'pain' are different. Language users who correctly apply these terms know the essence of what they refer to. The reason, says Swinburne, is that competent speakers who are favourably positioned with their faculties working properly and not subject to illusion know when and where terms like 'red' and 'pain' apply, they are able to make simple inferences to and from their application, and this kind of competence implies knowing what redness and pain are. It certainly seems plausible that correctly using a term like 'red' implies knowing in some sense what red is. If I am a competent speaker, favourably positioned with faculties in working order and not subject to illusion, then surely I can identify which things in the environment are red. It doesn't follow from this, however, that I know the conditions that are metaphysically necessary and sufficient for being red. By analogy, if you tell me that only people with a yellow ticket may enter the reception I can pick out the people who may enter the reception without knowing what earned them their yellow tickets. Being a competent doorman requires only being able to identify which people have a yellow ticket; it does not require me to know how or why they got it. Kripke and Putnam give us reason to think something analogous is often true of competent speakers.

Swinburne counters this with the suggestion that I cannot be wrong about something looking red to me. But exponents of the 
Kripke-Putnam view can concede this point. Even if I cannot be wrong about something looking red to me, I can still be wrong about something being red. One way of developing this idea is to say that terms like 'red' get their meanings from certain prototypical applications. We apply 'red' to objects whose surfaces reflect such-and-such wavelengths of light to the eyes of such-and-such observers under such-and-such conditions (Swinburne countenances some of these conditions with the expression 'favourably positioned with faculties in working order and not subject to illusion'). Things get called 'red' to the extent that they resemble the prototypes. Sometimes, however, we find ourselves in circumstances that do not satisfy the conditions that define the prototypes; objects look red to us that are not 'really' red; that is, that we would not call red if we saw them in prototypical circumstances (I see your tie in unusual lighting, and believe it is red, but recognize my mistake when we enter white light). If 'red' means something like this, then it is possible that redness might be identical to a surface property whose essence we do not know even though we can competently use 'red' to refer to objects having it. Likewise, redness could be a higher-order property such as the property of having a surface property that reflects such-and-such wavelengths of light in prototypical circumstances. In either case, Swinburne's property dualism does not follow.

I confess that I found it difficult to discern an argument in Mind, Brain, and Free Will that would rule out views of this sort. Two considerations that Swinburne advances seem to fall short. One is the point mentioned earlier that how something looks to people appears to be an extra fact about it beyond its having a certain reflectance spectrum. Exponents of the Kripke-Putnam view can readily concede this point. When we are talking about how things look to us, they can say, we are talking about a relation between a surface and an observer as opposed to a property of the surface taken by itself. Since relations are not intrinsic properties, facts about relations are not facts about intrinsic properties. It does not follow from this, however, that redness is not an intrinsic physical property, nor that it is not a physical relation.

Second, Swinburne appeals to the kind of argument J. J. C. Smart attributed to Max Black. ${ }^{1}$ If 'red' and 'reflecting such-and-such wavelengths of light' are not logically equivalent, as exponents of the Kripke-Putnam

${ }^{1}$ J. J. C. Smart, . 'Sensations and Brain Processes', in The Philosophy of Mind, V.C. Chappell, ed. (Englewood Cliffs: Prentice-Hall, Inc., 1962), pp. 160-172. 
account must concede, then the criteria for correctly applying the one term cannot be identical to the criteria for correctly applying the other. The differences between these criteria must ultimately boil down to differences among properties. There must be certain properties whose recognition by a competent speaker underwrites the correct use of 'red', and certain properties whose recognition by a competent speaker underwrites the correct use of 'reflecting such-and-such wavelengths of light. These properties, moreover, must be different, for it must be possible for competent speakers to recognize the instantiation of the properties that sanction the use of the one term while at the same time not recognizing the instantiation of the properties that sanction the use of the other. Consequently, it looks as though exponents of the KripkePutnam account must endorse a dualism of properties.

The problem with this argument is that by itself it does not support the dualism of physical and nonphysical properties that Swinburne looks to defend; it supports only the thesis that the properties which underwrite the correct use of 'red' must be different from those which underwrite the correct use of 'reflecting such-and-such wavelengths of light', and it does not follow from this alone that the former properties must be nonphysical and the latter physical. To appreciate this let us imagine for the sake of argument that physicalism is true, and that $P_{1}, P_{2}, \ldots, P_{n}$ are all the properties that exist. Since physicalism is true by assumption, $P_{1}, P_{2}, \ldots, P_{n}$ are all physical properties. Suppose now that competent speakers apply the predicate 'is red' to something if and only if it instantiates $P_{1}$, and that they apply the predicate 'reflects such-and-such wavelengths of light' to something if and only if it instantiates $P_{2}$. In that case, the properties that competent speakers must recognize to correctly apply the one predicate differ from the properties they must recognize to correctly apply the other, yet it does not follow that either predicate expresses a nonphysical property, for by assumption all properties are physical. The dualism that the argument supports is merely a dualism of conditions for correctly applying predicates or terms - a difference in what some philosophers call 'modes of presentation.' ${ }^{2}$ This does not by itself support a dualism of physical and nonphysical properties. To derive that conclusion a further premise is needed to the effect that the

${ }^{2}$ John Perry, Knowledge, Possibility, and Consciousness (Cambridge, Mass.: MIT Press, 2001); Ned Block, Consciousness, Function, and Representation: Collected Papers, Volume 1 (Cambridge, Mass.: A Bradford Book, 2007), Chapter 21, pp. 435-490. 
properties which fix the referents of terms like 'red' must be nonphysical. But it is difficult to see how exponents of the argument can endorse such a premise without either begging the question against their opponents or making tendentious assumptions about properties. ${ }^{3}$

Swinburne replies that critics who endorse the foregoing line of argument end up multiplying entities beyond necessity since modes of presentation are extra theoretical posits. But there are two things to say in response. First, it is not clear that modes of presentation are in fact extra theoretical posits. Modes of presentations are typically posited to explain why identity statements such as 'Cicero is Tully' are informative while identity statements such as 'Cicero is Cicero' are not. If properties $F_{1}, F_{2}, \ldots, F_{\mathrm{n}}$ are all of Cicero's properties, and competent speakers fix the referent of 'Cicero' by appeal to $F_{1}$ and the referent of 'Tully' by appeal to $F_{2}$, then the informativeness of 'Cicero is Tully' has a straightforward explanation: it is informative because the referents of 'Cicero' and 'Tully' are fixed by appeal to different properties. Likewise, if $F_{1}, F_{2}, \ldots, F_{n}$ are all the properties had by the property of redness (Swinburne admits that there are properties of properties), then one can explain the informativeness of the putative identity statement 'Redness is reflecting such-and-such wavelengths of light' in an analogous way: competent speakers fix the referent of 'redness' by appeal to $F_{1}$, and they fix the referent of 'reflecting such-and-such wavelengths of light' by appeal to $F_{2}$. Some philosophers choose to call properties like $F_{1}$ and $F_{2}$ 'modes of presentation'. Using this terminology does not add anything to the theoretical apparatus they must already endorse to make sense of informative identity claims, so it is not clear that modes of presentation amount to 'extra' theoretical posits, as Swinburne claims. Second, there are reasons to think that philosophers like Swinburne must themselves be committed to positing modes of presentation. Ostensibly any philosophers who want to explain informative identity statements must posit such modes or something very much like them, and presumably that includes philosophers like Prof. Swinburne. In addition, without modes of presentation Black's argument cannot get off the ground, for it requires that different properties fix the referents of expressions like 'red', on the one hand, and expressions like 'reflects such-and-such wavelengths of light', on the other. This gives us reason to think that Swinburne himself must tacitly endorse modes of presentation even if he chooses not to call them that.

${ }^{3}$ Block (ibid.) argues for this in detail. 
Based on the foregoing considerations it remains unclear how Swinburne rules out the Kripke-Putnam view. Consequently, it remains unclear why we should accept that terms like 'red' and 'pain' are informative designators in Swinburne's sense, and as a result it remains unclear why we should accept the property dualism Swinburne endorses.

\section{SWINBURNE'S ARGUMENT FOR SUBSTANCE DUALISM}

Similar worries attend Swinburne's argument for substance dualism. To appreciate this it's helpful to consider Swinburne's philosophical forebear, Descartes, and the exchange he had with his contemporary Antoine Arnauld, author of the fourth set of objections to the Meditations. Descartes argued that we could exist without bodies because thought was our only essential property. To support this premise Descartes compiled a list of the properties that people initially took themselves to have and argued that we could clearly and distinctly conceive of ourselves existing without each of the properties on the list - each, that is, except thought. We cannot form a (first-personal) conception of ourselves without thought, so Descartes concluded that we could not exist without it, and since this was the only property of which this was true, it must be our only essential property. Arnauld's worry about Descartes' argument was that the initial conception people had of themselves might be in some way impoverished, that people might have properties, perhaps even essential ones, of which they were entirely ignorant, and which therefore did not appear on Descartes' list. Since these properties would not have been subjected to Descartes' conceivability test, Descartes' conclusion would not follow; we could have essential properties of which we are entirely unaware. Descartes conceded to Arnauld that the conception we started with would have to comprise all our essential properties (it would have to be 'complete' as he put it), but he never explained why we should suppose that the conception we have of ourselves is complete in fact.

What was true of Descartes vis-à-vis Arnauld seems true of Swinburne vis-à-vis Kripke and Putnam. Kripke and Putnam made it evident that Arnauld's worry was not an abstract possibility; rather, our best concrete efforts at understanding the world have revealed that things often have properties, including essential ones, of which we can remain entirely unaware in our pedestrian dealings, and which for that reason do not factor into the meanings of the terms we use to refer to them. Just as it 
is unclear how Swinburne rules out a Kripke-Putnam account when it comes to properties like redness, it is unclear how he rules it out when it comes to substances like you and I. He argues that I cannot be wrong about what 'I' refers to in the way I can be wrong about what 'water' refers to:

'I' or 'Richard Swinburne' as used by me ... seem to be informative designators. If I know how to use these words, then ... I can't be mistaken about when to apply them ... I cannot know how to use the word ' $\mathrm{I}$ ' ... and still wonder whether it is I or someone else who is having that event ... My knowledge of how to use 'I', like my knowledge of how to use 'green' and 'square', means that I know the nature of what I am talking about when I use the word. (p. 158)

But it is unclear how Swinburne's conclusion follows from this. Even if I am necessarily right about what 'I' refers to, I can still be wrong about what essential properties I have. (By analogy, I can correctly admit all and only the yellow ticket holders while yet incorrectly conjecturing how they got the tickets.) It remains unclear, therefore, why we should believe that the competent use of 'I' implies knowing what I essentially am, and as a result it remains unclear how we ought to arrive at the conclusion that we are pure mental substances, ones that have only pure mental properties essentially.

The work of Arnauld, Kripke, and Putnam points to a general worry that has confronted Cartesian projects like Swinburne's since the seventeenth century. The arguments Cartesians advance typically assume that our concepts and the predicates and terms that express them leave out nothing essential to the things we think and talk about, that they are 'complete' in Descartes' sense, and as a result we can know how matters stand with regard to ourselves, our bodies, our powers, properties, and so on, merely by consulting our language and concepts. It is this assumption that Swinburne encapsulates in his claim that 'red,' 'pain', 'I', and other terms are informative designators, and that I've suggested he has failed adequately to defend.

The foregoing remarks criticize the idea that mental properties are our only essential properties, but are mental properties essential to us at all? I confess that I found Swinburne's argument for this claim rather difficult to follow. Its main premises appear to be these:

(1) If humans coexperience conscious mental events of different kinds (if, for instance, they simultaneously see the trees outside 
and smell the coffee brewing), then mental properties determine the physical boundaries of a substance.

(2) If mental properties determine the physical boundaries of a substance, then they in part determine what physical properties that substance has.

(3) If mental properties in part determine what physical properties a substance has, then that substance is a mental substance; that is, it has mental properties essentially.

The reasoning behind (1) appears to be this: Suppose that I coexperience mental events $m_{1}$ and $m_{2}$. We know empirically that mental events are caused by brain events, so let us suppose that $m_{1}$ and $m_{2}$ are caused by brain events $b_{1}$ and $b_{2}$, respectively. Since $m_{1}$ and $m_{2}$ are coexperienced by me, the parts of the brain involved in $b_{1}$ and $b_{2}$ must both be parts of me (if they were not, then the mental events they caused would not be coexperienced by one and the same substance as they are by me). The mental events I coexperience thus determine at least in part which physical things are parts of me. If that is true, then there is good reason to endorse premise (2), for if mental properties play a role in determining what parts I have, and those parts have physical properties which are attributable to me, then mental properties play a role in determining what physical properties I have as well. But now we come to a sticking point. If my mental properties partly determine what physical parts I have and hence what physical properties I have, it is still not evident how this implies that I have mental properties essentially, as premise (3) claims. To arrive at this conclusion Swinburne must assume that I have no physical properties other than those which are determined by my mental properties. It is plausible to suppose that I have no physical properties other than those which are determined by my physical parts, but why should we suppose that the only parts I have are ones which are determined by my mental properties? Couldn't I have parts which are mentally irrelevant, which are not involved in events that cause or are caused by mental events - hair, fingernails, white blood cells, even parts of the nervous system such as glial cells? And couldn't the continued existence of some of these mentally irrelevant parts be sufficient for my continued existence (as some animalists claim about the brainstem)? I couldn't discern an argument in Mind, Brain, and Free Will that would rule this out, so it remains unclear why we should accept premise (3), and hence why we should accept that we have mental properties essentially. 


\section{PHYSICAL PHENOMENA AND STRUCTURE}

A final point concerns Swinburne's notion of bodies and physical phenomena generally. A substance is mental according to Swinburne if it has mental properties essentially, and it is physical otherwise. This might strike some readers as a rather odd way of defining 'physical', for suppose that I am a ghostly being made of ectoplasm with properties that physics cannot even in principle describe, and that I have mental properties but only contingently (when, say, the ectoplasm achieves a certain state). By Swinburne's definition I count as a physical substance (and not a mental one) despite having no properties at all that can be described by physics. The reason for this odd result is that for Swinburne being physical has nothing to do with physics. His definition is like the Amish definition of 'English'. For the Amish, being English has nothing to do with being from England; it is simply not being Amish. Likewise, for Swinburne being physical is simply not being essentially mental. This is awkward for philosophers who are careful to distinguish biological, chemical, and other special scientific properties from physical ones (just as I imagine the Amish use of 'English' must be awkward for people who are careful to distinguish the Welsh, the Scottish, and others from the English).

This definitional point is important because I think it reveals a general tendency to overlook important distinctions within the natural world. For Swinburne, as for many other Cartesians, there is nothing about human bodies that would set them apart as special denizens of the physical universe. Contrast this with a view (one might call it a contemporary hylomorphic view) which claims that structure is a basic ontological and explanatory principle, one that concerns both what things essentially are and what they can do. Put a human in a leak-proof bag and then squash it with several tons of force. The contents of the bag no longer include a human being, nor can those contents think, feel, and act as they once could. What explains the difference pre- and post-squashing? Since the physical materials remain the same (none leaked out) we want to say that what changed was simply the way those materials were organized or structured, that this organization or structure was responsible not only for there being a human before the squashing, but also for that human having the distinctive capacities it had. A view along these lines has some empirical backing, as William Bechtel, a philosopher of neuroscience, observes: 
[T] he organization of ... components typically integrates them into an entity that has an identity of its own ... Organization itself is not something inherent in the parts... Accordingly, investigators who already understand in detail how the parts behave are often surprised by what happens when they are organized in particular ways... In virtue of being organized systems, mechanisms do things beyond what their components do ... Not only can one study the performance of a mechanism without knowing its component parts and their operations, but what the mechanism as a whole does is typically quite different than the operations performed by its parts ... As a result, organized mechanisms become the focus of relatively autonomous disciplines ... This autonomy maintains that psychology and other special sciences study phenomena that are outside the scope of more basic sciences. ${ }^{4}$

According to Bechtel, a complex whole - what he calls a 'mechanism' such as an organism, has an organization that confers on it capacities that are not had by its parts taken in isolation, and that cannot be reductively explained in terms of lower-level sciences. His work and that of others suggest that our best empirical descriptions and explanations of living behaviour posit organization (or structure, arrangement, order, configuration) as a basic ontological and explanatory principle.

Swinburne concedes that wholes are composed of parts arranged in certain ways, and that parts sometimes behave differently when incorporated into larger wholes. 'Nevertheless', he says, 'the causal properties of larger substances such as organisms are just the causal properties of their parts ...' (p. 32) For Swinburne, arrangement makes no causal difference to things. It might be an ontological principle insofar as it is in part what makes a whole what it is, but it is not an explanatory principle on Swinburne's view since it does not confer any powers on a whole beyond those conferred by its parts. Swinburne is not alone in thinking this. His position is the norm among Cartesians and also among physicalists. Yet if the hylomorphic alternative just described is viable, it could relieve some of the anxieties that motivate both substance dualism and physicalism, for it implies an antireductionism that preserves what is special about human existence without denying humans' essential

4 William Bechtel, 'Reducing Psychology while Maintaining its Autonomy via Mechanistic Explanations', in The Matter of the Mind, Maurice Schouten and Looren de Jong, Huib, eds. (Malden, Mass.: Blackwell Publishing, 2007), pp. 172-198 (pp. 174, 185-186). 
materiality. ${ }^{5}$ Distinctively human traits, it says, are due to our distinctively human structures, structures that are nevertheless essentially embodied in physical materials. And since structures are basic ontological and explanatory principles on the hylomorphic view, ones that confer powers on a thing beyond those conferred by its composing materials, the view is robustly antireductive. Seen by comparison with a view like this, the project of trying to preserve human distinctiveness by denying essential human materiality begins to lose some of its appeal.

There is clearly a great deal more to be said on this point and on Mind, Brain, and Free Will in general, but I hope what I've said is enough to contribute in a small way to a further discussion of Swinburne's work.

${ }^{5}$ I take what is special about human existence to include eschatological factors. Elsewhere, for instance, I've argued that a contemporary hylomorphic view is compatible with the doctrine of the resurrection; see my 'Hylomorphism and Resurrection', European Journal for Philosophy of Religion, 5 (2013), 197-224. 